\title{
CLÉMENCE BOULOUQUE: A NARRATIVA DE FILIAÇÃO COMO ESCRITA DO TRAUMA
}

Laura Barbosa Campos

Universidade do Estado do Rio de Janeiro

\section{RESUMO:}

As "narrativas de filiação" são manifestações contemporâneas do gênero autobiográfico, assim denominadas pelo teórico Dominique Viart desde meados da década de 1990. O número considerável de publicações que abarcam a temática da filiação, da herança e da transmissão levou Viart a considerá-las como um abrangente fenômeno de época. O presente artigo objetiva refletir sobre essa modalidade autobiográfica na perspectiva da inscrição do trauma. O corpus é composto por Mort d'un silence [Morte de um silêncio] (2003), narrativa na qual a escritora francesa Clémence Boulouque evoca a morte trágica de seu pai.

PALAVRAS-CHAVE: Narrativa de filiação. Trauma. Clémence Boulouque.

O século XX foi marcado por imensas contradições, ao mesmo tempo em que a modernidade trouxe o primado do racionalismo e grandes avanços tecnológicos, foi também um período de catástrofes:

Nós podemos pensar a humanidade ao longo do século XX como parte de uma sociedade que poderia ser caracterizada, sucessivamente, como pós-massacre dos Armênios, pós-Primeira Grande Guerra, pós-Segunda Guerra Mundial, pós-Shoá, pós-Gulag, pós-guerras de descolonização [...]. Estar no tempo "pós"-catástrofe significa habitar essas catástrofes (SELIGMANN-SILVA, 2002, p. 136). 
Nesse contexto "pós-catástrofe", a noção de trauma, central no pensamento psicanalítico, se disseminou também por boa parte da cultura, uma vez que a violência, em suas diversas formas, tem sido lamentavelmente determinante para nossa autocompreensão. A literatura de língua francesa se revelou um terreno fértil para as escritas de si mobilizadas por eventos traumáticos, sejam eles de caráter coletivo ou individual.

A partir do final do século XX, emerge uma modalidade específica de autobiografia, denominada "narrativas de filiação" pelo teórico Dominique Viart, que já as considera como um fenômeno de época. É nessa categoria de textos que se inscreve a publicação que analiso aqui pelo prisma da inscrição do trauma. Tratarei da obra Mort d'un silence [Morte de um silêncio] (2003), de Clémence Boulouque (1977), escritora francesa de origem judaica.

Em um primeiro momento, enfoco uma breve evolução da noção de trauma para, em seguida, apontar algumas questões relacionadas às narrativas de filiação e, por fim, passar ao estudo do texto de Boulouque.

\section{A noção de trauma: alguns apontamentos}

Não cabe aqui retraçar todo o vasto e complexo percurso da teoria do trauma, não obstante, destaco o fato de se tratar de uma noção presente desde a origem da psicanálise.

O vocábulo trauma provém do grego e, etimologicamente, significa ferida e deriva do verbo furar, ou seja, designa uma ferida realizada com efração. O termo traz, portanto, a ideia de arrombamento ou de ruptura. Na psicanálise, a palavra foi inicialmente ligada ao vocabulário clínico de Jean-Martin Charcot em seus estudos sobre a "histeria traumática", nos quais se pensa a respeito da anormalidade psíquica como decorrente apenas de um trauma físico (ROUDINESCO; PLON, 1998, p. 337). Essa concepção inicial do termo influenciará Breuer e Freud nos primeiros estudos sobre os fatores etiológicos da histeria, mas os dois médicos transformam a teoria charcotiana e agregam uma natureza sexual ao trauma.

É a partir da Primeira Guerra Mundial, pela observação dos soldados e sobreviventes do conflito, que Freud escreve um texto central em sua obra: Além do princípio do prazer. Sua relevância se deve ao fato de tentar dar conta dos traumatizados de guerra e realizar uma mudança na apreensão do funcionamento do aparelho psíquico.

O pai da psicanálise observa que ocorre uma fixação da vivência traumática e uma repetição frequente do mesmo episódio doloroso sob a 
forma de sonhos. Há uma retenção na situação de ruptura e, para Freud, ocorre um fenômeno ligado ao desequilíbrio da economia psíquica. Segundo Laplanche e Pontalis, o trauma é um "acontecimento da vida do sujeito que se define por sua intensidade, pela incapacidade em que se encontra o sujeito de reagir a ele de forma adequada, pelo transtorno e pelos efeitos patogênicos duradouros que provoca na organização psíquica" (LAPLANCHE; PONTALIS, 1992, p. 522).

Após a morte de Freud (1939), vários autores desdobraram e desenvolveram a noção de trauma, principalmente com estudos relacionados aos sobreviventes dos campos de concentração e, em seguida, aos veteranos da guerra do Vietnã.

Na década de 1980, a Associação Americana de Psiquiatria reconheceu oficialmente uma nova categoria associada à ideia de trauma e denominada de transtorno de estresse pós-traumático (TEPT). O transtorno incluiu sintomas anteriormente diagnosticados como "choque de bombardeios, estresse de combate, síndrome de estresse posterior e neuroses traumáticas"' (CARUTH, 1995, p. 3). Cathy Caruth aponta, como característica recorrente do TEPT, a presença de uma reação, muitas vezes tardia, proveniente de um ou mais eventos catastróficos, sob a forma de alucinações, sonhos, pensamentos ou comportamentos intrusivos e repetitivos (CARUTH, 1995, p. 15).

Em Trauma and Recovery (1992), Judith Herman destaca que a recuperação demanda uma retomada de controle pelo sujeito das lembranças e dos sintomas associados ao TEPT e ressalta a importância da verbalização como objetivo final (HERMAN, 1992, p. 177)2 , insistindo na construção da narrativa verbal do evento traumático como ferramenta de domínio e integração das excitações no psiquismo (HERMAN, 1992, p. 181).

A fase narrativa é, portanto, determinante para a reintegração, reorganização e controle da vivência dolorosa, na medida em que a vítima reelabora o "passado que não passa" e se faz constantemente presente em forma de sintomas. O traumático não é o acontecimento em si, mas a sua lembrança. Não é outra a ideia que se expressa na famosa afirmação dos "Estudos sobre a histeria": "as histéricas sofrem principalmente de reminiscências" - ao que se pode acrescentar: reminiscências que são traumáticas.

Talvez seja esse um dos motivos pelos quais tantas autoras e tantos autores vêm recorrendo às narrativas de filiação como um poderoso dispositivo de memória e de reinvenção da vida. Trata-se de uma escrita 
ligada à contemporaneidade e a uma época que se volta para si mesma, problematizando o impacto das tragédias que atravessaram o século XX.

\section{As narrativas de filiação}

A produção literária francesa do final do século XX, principalmente a partir da década de 1980, indica uma modificação estética, qual seja, o abandono de preocupações estritamente formais e o primado da autorreferencialidade da escrita, tão caros ao Nouveau Roman e ao Estruturalismo, em prol do retorno da literatura à transitividade, ou melhor, a objetos exteriores a ela, dentre os quais "a questão da expressão e da representação do Sujeito figura em primeiro plano"3 (VIART; MERCIER, 2009, p. 95).

A prática autobiográfica do século XXI recusa a ambição totalizadora canônica, sem entretanto abdicar de um pacto de leitura referencial, na linha proposta por Philippe Lejeune desde 1973. Em Le propre de l'écriture de soi (2007), Françoise Simonet-Tenant destaca algumas tendências das escritas de si na literatura francesa atual. A autora enfatiza uma propensão da narrativa autobiográfica a "se miniaturizar" e a mostrar uma preferência pelo fragmento em detrimento da totalidade, concentrando-se em breves momentos determinantes da existência, como a evocação de uma perda, um encontro ou uma separação. Acredito que o ponto nodal seja muitas vezes determinado pela presença de um evento traumático, como acontece em Mort d'un silence (2003), relato suscitado pelo suicídio da figura paterna.

Simonet-Tenant aponta, também, a tendência das autobiografias a se hibridizarem com outros gêneros, não apenas com o romance, mas também com outras manifestações das escritas de si. Observa-se, por exemplo, a aproximação entre o gênero biográfico e as "narrativas de filiação".

Desde meados da década de 1990, Dominique Viart forjou o termo "narrativa de filiação" para destacar um número considerável de publicações que abarcam a temática da filiação, da herança e da transmissão mobilizando estratégias recorrentes. "A noção foi sugerida, pela primeira vez, durante o colóquio États du roman contemporain, 6-13 juillet 1996" (NORONHA, 2014, p. 114).

De Annie Ernaux (La place, une femme) a Leila Sebbar (Je ne parle pas la langue de mon père), ou ainda Émmanuel Carrère (Un roman russe) e Dany Laferrière (L'énigme du retour), a narrativa de filiação tornou-se uma das manifestações autobiográficas mais recorrentes na atualidade. Trata-se de uma tendência ampla e que, apesar de contemplar varia- 
ções narratológicas, pode ser considerada como um fenômeno de época e englobar tanto textos referenciais como autoficcionais. Segundo Viart, assim como o romance, as "narrativas de filiação" estão intimamente ligadas ao momento histórico-cultural no qual se inserem. Vale lembrar que, apesar de se caracterizarem por uma pesquisa sobre a ancestralidade, esses textos não buscam restituir trajetórias individuais para retomar uma história coletiva, nos moldes das grandes sagas do século XIX. Trata-se, agora, de uma temática relacionada à crise da escrita, diante do questionamento de referenciais, valores e discursos. As "figuras parentais estão destituídas do valor de exemplaridade. São identidades malsucedidas, incertas, inacabadas"4 (VIART, 2009, p. 94).

Esses narradores que investigam uma ancestralidade da qual se sentem herdeiros, em geral problemáticos, falam do outro para, na verdade, falar de si, operam apenas um deslocamento. "O relato do outro - pai, mãe ou tal antepassado - é o desvio necessário para chegar a si, para se compreender nessa herança: a narrativa de filiação é um substituto da autobiografia $^{5}$ (VIART, 2009, p. 80). Carine Trevisan corrobora a afirmação de Viart e destaca: "Trata-se de textos que assumem a forma de uma busca ou de uma investigação sobre a ascendência, questionando os laços de filiação, o processo e o objeto da transmissão, enfim a identidade do narrador como herdeiro problemático"6 (TREVISAN, 2004, p. 7).

Sendo assim, são obras que problematizam a transmissão da herança e buscam dar conta de uma falta: rupturas, segredos de família e figuras parentais ausentes são recorrentes. Todos esses aspectos tornam o passado bastante obscuro, daí a postura investigativa apontada por Trevisan. É nessa categoria de textos que se insere a obra que analiso em seguida.

\section{Clémence Boulouque: Mort d’un silence (2003)}

Je n'ai pas échappé à mes souvenirs.

Clémence Boulouque

O atentado ao World Trade Center, em Nova York, é o ponto de partida do livro Mort d'un silence, prêmio Fénéon em 2004 e primeira publicação da autora. Jornalista e crítica literária, Clémence Boulouque é filha do juiz Gilles Boulouque, o magistrado encarregado da divisão antiterrorista francesa nos anos 1980, morto tragicamente quando Clémence tinha apenas treze anos. 
A narrativa autobiográfica recobre essencialmente o período de 1986 até a morte do juiz, mesclando acontecimentos da esfera pública à dimensão íntima e privada. $\mathrm{O}$ relato parte da nomeação de Boulouque para a nova função, após os atentados parisienses ligados ao grupo Hezbollah e ao conflito entre o Irã e o Iraque, em 1986. Clémence tem, então, apenas nove anos de idade, e o texto descreve o cotidiano de uma família comum da classe média francesa. A tranquilidade e leveza desse período se contrapõem ao terrível desenrolar dos acontecimentos e determinam uma espécie de ruptura entre uma vida luminosa e a subsequente fase sombria. A narradora afirma: "as lembranças dessa primeira vida são banhadas de claridade"7 (BOULOUQUE, 2003, p. 25). Essa demarcação rigorosa entre dois períodos antagônicos remete também ao ego cindido da narradora, por consequência da experiência traumática.

O novo cargo de Gilles Boulouque impõe, em um primeiro momento, uma mudança radical no estilo de vida da família. Ao longo de nove capítulos, o leitor acompanha a degradação de um ambiente cada vez mais tenso, em meio ao delicado contexto político francês e internacional. As novas responsabilidades do juiz deixam toda a família sob os holofotes, tornando-se alvo não apenas dos terroristas, mas também da opinião pública. A rotina de todos se transforma: presença permanente de seguranças, férias cada vez mais escassas e tumultuadas, insultos na escola e na vizinhança e, sobretudo, a forte pressão político-midiática sofrida pelo juiz são aspectos decisivos para o triste desfecho, o suicídio de Gilles Boulouque em dezembro de 1990.

Além dos nove capítulos, o livro apresenta um preâmbulo no qual a narradora explica que decidira partir para viver na metrópole norte-americana, longe de suas lembranças de infância, mas que fora surpreendida pelos acontecimentos quando, em 11 de setembro de 2001, o World Trade Center deixa de existir. Lê-se: "Existirão apenas os barulhos, as imagens desses aviões em colisão, as Torres desmoronando. Somente os ausentes. O terrorismo, os ausentes" (BOULOUQUE, 2003, p. 13-14). O trecho situa o atentado norte-americano como elemento desencadeador da cena do trauma, a saber, o suicídio paterno.

Outro aspecto relevante no trecho citado, mas que ocorre também ao longo de todo o texto, diz respeito ao plano formal. A ausência de sintaxe pesada ou, pelo menos, a pouca importância dada às ligações sintáticas, caracteriza todo o tecido narrativo de Boulouque. Há muitas frases nominais breves e as orações subordinadas circunstanciais, por exemplo, 
são relativamente raras, sua escrita parece desenhar um mundo da descontinuidade. $\mathrm{O}$ estilo está relacionado ao universo traumático em desagregação, ao mundo da fissura, cujas marcas textuais busco explorar.

Em Mort d'un silence, a utilização recorrente de aposiopeses está associada ao evento traumático. Trata-se de uma figura de linguagem que produz uma elipse final por meio de uma interrupção súbita e intencional no discurso, ou seja, engendra um efeito de silêncio brusco, ou, em termos psicanalíticos, um mecanismo de defesa com o objetivo de frear a verbalização de determinado conteúdo psíquico. "É o que acontece, por exemplo, no trecho que mimetiza uma carta que a menina Clémence teria escrito a seu avô morto:

Domingo, 10 de junho de 1990, 23 horas 23,

Querido vovô,

Estou aqui. Sentada na minha cama, com a caneta na mão, escrevo para você. Na quarta-feira, fará seis meses que você se foi. Muitas coisas irromperam em nossas vidas: o papai tá no terrorismo...9 (BOULOUQUE, 2003, p. 87).

A suspensão abrupta se evidencia graficamente pelo sinal de reticências, criando uma tensão entre o que é exposto e o que é encoberto à consciência, permanecendo como recalque. Observa-se o mesmo tipo de estrutura no trecho: "Eu sou a filha de um homem que era magistrado, que talvez não tenha suportado o sistema, que tenha talvez se equivocado, que tenha talvez sido reto demais e frágil demais, que foi ceifado, que..." (BOULOUQUE, 2003, p. 58). Após se definir como a "filha de", portanto a partir do pai, e enumerar aspectos relacionados ao juiz, o enunciado é, mais uma vez, abruptamente silenciado. O pai é considerado como alguém que foi extirpado da vida, portanto vítima de uma intensa violência. Sintomaticamente, a narradora interrompe o relato nesse ponto, quando parece que a situação traumática viria à tona em toda a sua extensão, como se a memória acionasse seus dispositivos de proteção.

No trecho supracitado, fica claro também o desejo de reabilitação da instância paterna, característica recorrente das narrativas de filiação, tal como apontado por TREVISAN (2004, p. 11). O texto de Boulouque concentra-se, principalmente, na busca da memória dos últimos anos de convívio com o pai, cuja vida é reescrita deliberadamente como forma de reparação da figura parental, mas também, e sobretudo, de elaboração 
da situação traumática. A narradora afirma: "rasuro sua vida [do pai] em vez de renunciar a ela" (BOULOUQUE, 2003, p. 127) ${ }^{11}$. Em última análise, como a narrativa de filiação demanda uma construção identitária por meio de um desvio pela história do outro (nesse caso, do pai), ao "rasurar" a vida do pai, a narradora reconstrói também sua própria história.

Da mesma forma que as aposiopeses podem ser lidas como marcas textuais da inscrição do trauma, a paronomásia também é uma figura retórica que, no texto de Boulouque, pode ser associada ao evento traumático. Trata-se de um recurso linguístico que extrai expressividade de termos parônimos, ou seja, palavras parecidas no som e/ou na grafia, quase homônimos. A frase: "Le terrorisme, mon père, ma perte" 12 produz uma alta densidade poética decorrente, principalmente, da aliteração em [per] no original em francês. Ao combinar vocábulos que apresentam semelhanças fônica e mórfica, como père e perte, a autora aproxima-os, também, semanticamente. Além disso, a convergência entre "pai" e "perda" é acentuada pela duplicação dos pronomes possessivos meu e minha, em "meu pai, minha perda".

A acribia topográfica e temporal ocupa um lugar central na descrição das lembranças da narradora, que enumera as cidades onde esteve em diferentes épocas, com precisão de detalhes. Tal registro confere, em muitos momentos, um tom documental ao relato de Boulouque. Já no incipit, lê-se: "Nova York, setembro de 2001". A narradora também fornece informações relativas ao cotidiano de uma época, quase um " $J e$ me souviens" à la Perec, como se tentasse se agarrar a referenciais e a elementos concretos do dia a dia na tentativa de preservar os vestígios de um determinado tempo:

Inverno de 1986 - a cantora Elsa acabava de ficar em primeiro lugar no Top 50, meu irmão militava contra o projeto de lei da privatização das universidades do ministro Devaquet. É a partir desse período que comecei a tomar os fatos da atualidade como referência para fixar na memória os acontecimentos da minha vida (BOULOUQUE, 2003, p. 36). ${ }^{13}$

Paradoxalmente, ao lado das rigorosas precisões espaço-temporais e de detalhes aparentemente anódinos do cotidiano, a narradora lamenta o desaparecimento de lembranças significativas. Há uma ausência de nexo entre o que é retido na memória e sua importância psíquica. $\mathrm{O}$ caráter insignificante das cenas se choca com a riqueza de minúcias com as quais são contadas. Algumas memórias de infância da narrativa de Boulouque podem ser lidas do mesmo ponto de vista de Freud a propósito das "lem- 
branças encobridoras", que diz: "O conceito de uma lembrança encobridora deve seu valor enquanto lembrança, não a seu conteúdo próprio, mas às relações existentes entre aquele conteúdo e algum outro, que foi esquecido" (FREUD, 1988, p. 48). O mecanismo psíquico que opera neste caso, diz Freud, é o deslocamento. A lembrança encobridora é o resultado do processo de recalcamento daquilo que é significativo, substituído na memória por uma outra imagem mnemônica.

A narradora de Mort d'un silence aponta a existência de um fenômeno semelhante às "lembranças encobridoras", tal como descritas por Freud. Ela se surpreende por conservar a lembrança de uma greve da rede ferroviária, durante o Natal dos seus nove anos de idade. Demonstra espanto pela presença daquilo que denomina de "lembrança inútil" e que acredita estar ocupando o lugar de outras lembranças que gostaria de ter tido preservadas (BOULOUQUE, 2003, p. 37).

A memória do trauma se situa, exatamente, nesse espaço do entre. Ela demanda uma elaboração discursiva, mas é sistematicamente silenciada, interrompida nas aposiopeses ou encoberta por imagens substitutas. Aquilo que chamo aqui de manifestações do trauma no plano formal, assim como as "lembranças encobridoras", expressam, justamente, um conflito dessa ordem.

\section{Considerações finais}

Clémence Boulouque, autora francesa de origem judaica, reescreve a história do drama familiar em torno da figura paterna e, por conseguinte, a sua autobiografia em Mort d'un silence. A morte, como evidenciado desde o título do livro, ocupa uma posição central na obra, que apresenta uma emblemática epígrafe composta por versos do poeta Paul Celan: "Conte as amêndoas, / conte o que era amargo e manteve-o acordado, / conte-me entre tudo isso"14.

A escolha do autor dos versos, por si só, já é eloquente. Assim como Boulouque, Celan é um escritor de origem judaica marcado pelo trauma da morte de seus pais em campos de concentração da Segunda Guerra Mundial. Na poesia de Celan, o sujeito é indissoluvelmente ligado à sua posição de sobrevivente. Em "Conte as amêndoas", a súplica do poeta pode ser lida como um desejo de comunicação com os mortos, chave de leitura com a qual Boulouque estabelece uma afiliação, ou seja, uma identificação por meio de uma relação horizontal que independe do parentesco e difere-se, nesse sentido, da filiação. A temática da amêndoa e 
da amendoeira compreende uma complexa rede de significados. Na tradição judaica, o fruto é associado à visão, devido ao seu formato semelhante aos olhos. Já a amendoeira é conhecida como a "árvore do despertar", por conta de sua floração precoce, antes do fim do inverno.

Por outro lado, apesar de toda simbologia positiva relacionada à amêndoa, que Boulouque explora mais a fundo em livro posterior, em $A u$ pays des macarons (2005), a amêndoa adquiriu mais recentemente um significado trágico. A partir da Shoá, paradoxalmente, o fruto da "árvore do despertar" também passou a se relacionar com a morte e com o genocídio dos judeus, devido ao fato de ser a base para a fabricação do gás Zyclon-B, composto letal utilizado pelos nazistas nas câmaras de gás dos campos de extermínio. Desde a Shoá, então, a árvore bíblica e seu fruto adquiriram uma fúnebre correlação.

Além da epígrafe de Celan, Mort d'un silence apresenta como excipit versos do poeta russo Ossip Mandelstam ${ }^{15}$, cuja alcunha era, justamente, "ramo de amendoeira", tradução literal de seu nome de origem germânica. Mandelstam teve, igualmente, um destino trágico, foi perseguido e morto pelo regime stalinista. Em Au pays de macarons, a autora explica a decisão de "enquadrar" sua voz em torno dos versos dos dois poetas: "era preciso que o relato sobre meu pai fosse aberto e fechado por suas presenças [de Celan e Mandelstam], duas sombras sem as quais o mundo me pareceria menos... mais... sem as quais eu me sentiria um pouco mais sozinha" (BOULOUQUE, 2005, p. 28). ${ }^{16}$

Com base na autópsia de um drama familiar, o suicídio do juiz Gilles Boulouque, Clémence Boulouque constrói sua narrativa de filiação pelo prisma da inscrição do trauma. A autora percorre, assim, o caminho apontado como fundamental por Judith Herman, a saber, a verbalização do evento traumático. Ao convocar Celan e Mandelstam como molduras de seu texto dedicado ao pai, a escritora também articula traumas coletivos à dimensão íntima e pessoal. Boulouque abre, assim, um espaço de homenagem às vítimas de duas grandes catástrofes do século $\mathrm{XX}$, os regimes totalitários de Hitler e Stalin. 


\section{CLÉMENCE BOULOUQUE: THE AFFILIATION NARRATIVE AS THE WRITING OF TRAUMA}

ABSTRACT:

The "affiliation narratives" are contemporary expressions of the autobiographical gender, so-called by the theorist Dominique Viart since the middle of the 1990's. A great number of publications dealing with themes of affiliation, heritage and transmission took Viart to consider them as an involving phenomenon of the time. This article aims at reflecting on this autobiographical kind coming from the perspective of the inscription of the trauma. The corpus is composed by Mort d'un silence (2003), a narrative which brings the French writer Clémence Boulouque's evocation of her father's tragical death.

KEYWORDS: Affiliation narrative. Trauma. Clémence Boulouque.

NOTAS

1 "shell shock, combat stress, delayed stress syndrome, and traumatic neuroses". As traduções são minhas.

2 "The ultimate goal [...] is to the story, including its imagery, into words" (HERMAN, 1992, p. 177).

3 "la question de l'expression et de la représentation du Sujet figure au premier plan."

4 "les figures parentales sont destituées de leur valeur exemplaire. Elles sont des identités mal épanouies, incertaines, inachevées."

5 "Le récit de l'autre - le père, la mère ou tel aieul - est le détour nécessaire pour parvenir à soi, pour se comprendre dans cet héritage: le récit de filiation est un 
substitut de l'autobiographie" (grifo do autor).

6 'Il s'agit des textes qui prennent la forme d'une quête ou d'une enquête sur l'ascendance, s'interrogent sur les liens de filiation, le processus et l'objet de la transmission, enfin sur l'identité du narrateur comme héritier problématique " (TREVISAN, 2004, p. 7).

7 "les souvenirs de cette première vie sont baignés de clartés."

8 "Il n'y a plus que les bruits, les images de ces avions qui le percutent, de ces tours qui s'effondrent. Plus que des absents. Le terrorisme, les absents."

9 "Dimanche 10 juin 1990, 23 heures 23, Mon cher papi, Je suis là. Assise sur mon lit, un stylo à la main, je t'écris. Mercerdi cela fera six ans que tu es parti. Comme ça. Beaucoup de choses ont jailli de notre vie : papa fait du terrorisme" (BOULOUQUE, 2003, p.87).

10 “Je suis la fille d'un homme, qui était magistrat, qui n'a peut-être pas suporté le système, qui s'est peut-être trompé, qui a peut-être été trop droit et trop fragile, qui en a été fauché, qui..." (BOULOUQUE, 2003, p. 58).

11 “qui rature sa vie au lieu d'y renoncer” (BOULOUQUE, 2003, p. 127).

${ }^{12}$ Vale destacar que a sequência [per pert] desaparece na tradução do francês para o português.

${ }^{13}$ L'hiver 1986, - la chanteuse Elsa venait de prendre la première place du Top 50 , mon frère militait contre le projet de loi sur les universités privées du ministre Devaquet. C'est à partir de cette période que j'ai commencé à prendre des repères dans l'actualité pour arrimer dans ma mémoire les événeéments de ma vie" (BOULOUQUE, 2003, p. 36).

${ }^{14}$ Tradução livre do francês: "Compte les amandes, / Compte ce qui était amer et t'a tenu en éveil, compte-moi au nombre de tout cela"

15 "Le pas qui nous porte sera hors de portée. / Immortelles, les fleurs. Le ciel demeure entier. Et ce qui adviendra n'est rien qu'une promesse."

16“il fallait que le récit sur mon père soit ouvert et fermé de leurs deux présences, leurs deux ombres nas lesquelles le monde m'aurait semblé moins... plus... sans lesquelles je me serais sentie un peu plus seule" (BOULOUQUE, 2005, p. 28). 


\section{REFERÊNCIAS}

BOULOUQUE, Clémence. Mort d'un silence. Paris: Gallimard, 2003.

. Au pays des macarons. Paris: Mercure de France, 2005.

CARUTH, Cathy. (Org.). Trauma: Explorations in Memory. Baltimore and London: The Johns Hopkins University Press, 1995.

. Unclaimed Experience: Trauma, Narrative and History. Baltimore, Maryland: The Johns Hopkins University Press, 1996.

FIGUEIREDO, Eurídice. A narrativa de filiação de escritores judeus brasileiros. In: CHIARELLI, Stefania; OLIVEIRA NETO, Godofredo de (Org.). Falando com estanhos: o estrangeiro e a literatura brasileira. Rio de Janeiro: 7Letras, 2016. FREUD, S. Estudos sobre a histeria [1893-1895]. Rio de Janeiro: Imago, 1990. V. II.

. Além do princípio do prazer. In: Obras completas. São Paulo: Companhia das Letras, 2010. V. 14 (1917-1920).

. Sobre a psicopatologia da vida cotidiana: considerações sobre o esquecimento, os lapsos de fala, o equívoco, a superstição e o erro. São Paulo: Escala, 1988.

HERMAN, Judith Lewis. Trauma and Recovery. Nova York: Haper Collins, 1992.

LAPLANCHE, J.; PONTALIS, J. B. Vocabulário da psicanálise. Tradução de Pedro Tamen. São Paulo: Martins Fontes, 1992.

LEJEUNE, Philippe; NORONHA, Jovita Maria Gerheim (Org.). O pacto autobiográfico: de Rousseau à internet. Tradução de Jovita Maria Gerheim Noronha e Maria Inês Coimbra Guedes. Belo Horizonte: UFMG, 2008.

NORONHA, Jovita M. Gerheim. Em nome do pai. Organon, v. 29, p. 113-134. Porto Alegre, 2014.

PINÇONNAT, Crystel, TREVISAN, Carine (Dir.). Transmissions et Filiations

- Revue des Sciences Humaines. Lille: Presses Universitaires du Septentrion, n. 301, 2011.

ROUDINESCO, E.; PLON, M. Dicionário de psicanálise. Rio de Janeiro: Jorge Zahar, 1998.

SELIGMANN-SILVA, Márcio. Literatura e trauma. Revista Pro-posições, v. 13, n. 3, p. 135-153, set./dez. 2002.

. Narrar o trauma: escrituras híbridas das catástrofes. Revista Gragoatá, 
n. 24 , p. $101-107,1^{\circ}$ semestre de 2008.

SIMONET-TENANT, Françoise (Dir.). Le propre de l'écriture de soi. Paris: Teraèdre, 2007.

TREVISAN, Carine; PINÇONNAT, Crystel (Dir.). Transmissions et Filiations - Revue des Sciences Humaines. Lille: Presses Universitaires du Septentrion, 2004.

VIART, Dominique; MERCIER, Bruno. La littérature française au présent: héritage, modernité, mutations. Paris: Bordas, 2009.

Recebido em: 31/08/2017

Aceito em: 07/12/2017 